\title{
Peritoneal Adenomatoid Tumor
}

National Cancer Institute

\section{Source}

National Cancer Institute. Peritoneal Adenomatoid Tumor. NCI Thesaurus. Code C7354.

A rare, benign neoplasm that arises from the peritoneum and is characterized by the presence of gland like structures. Cytologic atypia is absent. 